\title{
Novel Asymmetric U-Shaped Slot Antenna with WLAN Application
}

\author{
Qiang Chen, Hou Zhang, Tao Zhong, \\ Xue-Liang Min \\ Air Force Engineering University, Air and Missile \\ Defense College, Xi'an, Shaanxi Province, China 710051 \\ E-mail: cqky1989@126.com
}

\author{
Lu-Chun Yang \\ China Mobile (Shenzhen) Limited, Shenzhen, Guangdong \\ Province, China 518048 \\ E-mail: cqky1989@126.com
}

\begin{abstract}
A novel asymmetric U-Shaped slot antenna with WLAN application is proposed and fabricated. The proposed antenna consists of an asymmetric U-shaped slot and an inverted L-shaped slot which are designed to applied to WLAN devices, in addition, fed by a coplanar waveguide (CPW) Furthermore, Good agreement is achieved between the measurement and simulation, which indicates that a 10-dB bandwidth of $21.8 \%$ from 2.25 to $2.8 \mathrm{GHz}$ which completely cover the WALN $(2.4-2.48 \mathrm{GHz})$ band is covered in the designed antenna. Meanwhile, compared to other recent works, a single layer structure, and a more compact size are the key features of the proposed antenna.
\end{abstract}

Keywords-WLAN; slot antenna; coplanar waveguide (CPW)

\section{INTRODUCTION}

Due to its uniplanar and compact design, large impedance bandwidth and bidirectional / omnidirectional radiation patterns, increased freedom for applying perturbations in comparison to a micro strip feed for the design of the active-integrated antennas, the slot antenna fed by CPW is advantageous for feeding arrangements.

In published works, multi-layer or multi-feed configurations have been applied in achieving a WLAN band antenna, which have been considered complicate to realizing the desired antenna [1-10]. In this case, configurations of single-feed and single-layer are more desired in the proposed antenna[11-12]. Based on this, slot configurations fed by CPW can be used for antenna structure design, while having the potential to obtain WLAN bandwidths of operation [13-15].

A novel CPW-Fed d slot antenna, characterized by applied to the WLAN devices, is proposed. Moreover, it's realized by a single-layer and single-feed configuration. Compared with published antennas, the proposed antenna with a size of $50 \mathrm{~mm}$ by $54 \mathrm{~mm}$ is more compact. Besides, the designed antenna is characterized by low cost, low profile and simple structure.

\section{ANTENNA STRUCTURE}

The geometry of the proposed antenna is depicted in Fig.1 (a). The proposed antenna is printed on a square FR4 substrate with a dielectric constant of 4.4 , loss tangent of 0.02 and thickness of $1.6 \mathrm{~mm}$. The overall dimensions of the antenna are $50 \mathrm{~mm} \times 54 \mathrm{~mm} \times 1.6 \mathrm{~mm}$. The antenna is fed by a CPW line with a $50 \mathrm{ohms}$ characteristic impedance, characterized by its length $\mathrm{Lf}=19.9 \mathrm{~mm}$, width $\mathrm{Wf}=2.7$ $\mathrm{mm}$ and gaps on both sides width $\mathrm{g}=0.5 \mathrm{~mm}$. An inverted L-shaped slot is etched on the lower left corner of the square, and an asymmetric U-shaped slot on the right, optimization of the dimensions of the slots and CPW feed line are made and shown in detail in Table I. A compensatory structure is employed to achieve WLAN application performance by the proposed CPW-fed antenna. Moreover, the antenna has a single layer with all metal patches printed on the top of the substrate.

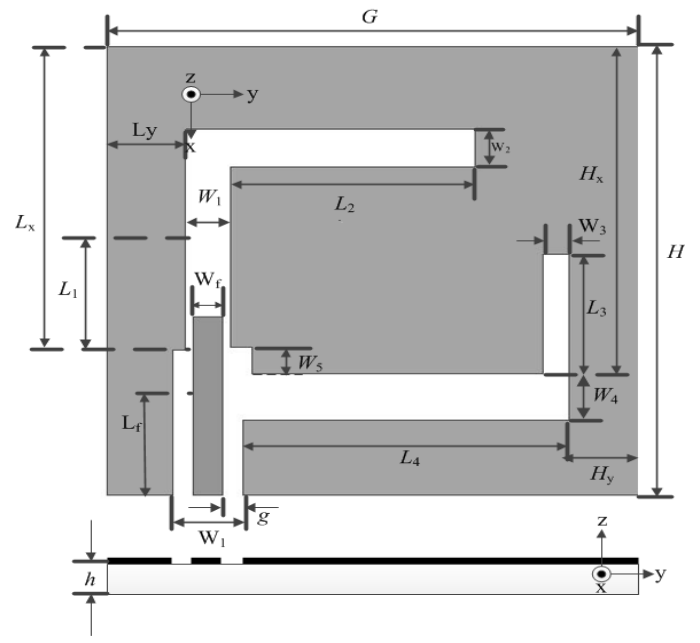

Figure 1. Configuration of antenna structure of the proposed CPW-Fed slot antenna and its prototype.

\section{SIMULATION AND MEASUREMENT RESULTS}

As listed in Table I, all dimensions of the proposed antenna have been optimized according to the results of numerical analysis.

The proposed antenna was initially simulated using HFSS and then fabricated with the optimized dimensions as shown in Fig. 1(b) with a photograph. Simulated and measured results of reflection coefficients of the proposed antenna are illustrated in Figs. (a) and (b). As shown in figures, the measured impedance bandwidths are $21.8 \%$ from 2.25 to $2.8 \mathrm{GHz}$. The simulated and measured $|\mathrm{S} 11|$ are in a good agreement as shown in figures. Though, shown in Figs, due to the poor quality of the SMA connector used and fabrication tolerance during measurements, there are also some mismatches between simulated and measured results. Meanwhile, the variation trends of the measured and simulated result are corresponding to each other. 


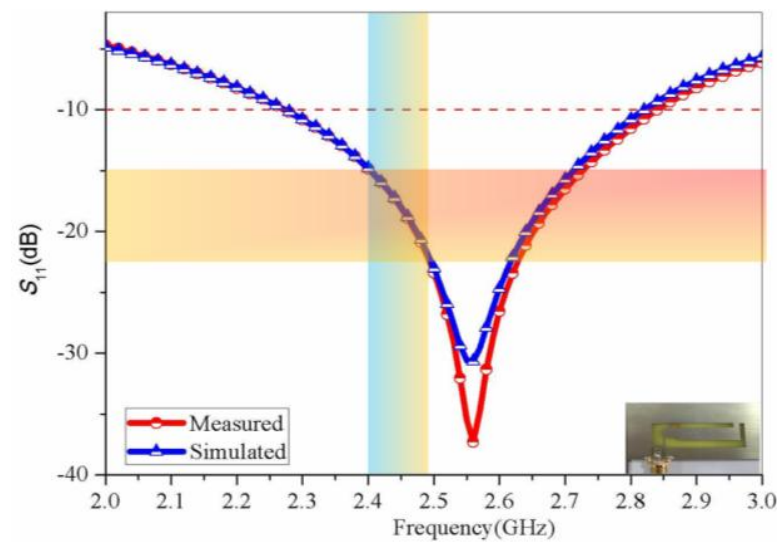

Figure 2 Simulated and measured reflection coefficients of the proposed antenna in the lower and upper band.

TABLE I. OPTIMAL DIMENSIONS OF THE PROPOSED ANTENNA

\begin{tabular}{cc|cc}
\hline Dimension & Size $(\mathrm{mm})$ & Dimension & Size $(\mathrm{mm})$ \\
\hline$G$ & 55 & $W_{2}$ & 4.2 \\
$H$ & 50 & $L_{3}$ & 13.4 \\
$L_{\mathrm{x}}$ & 33.8 & $W_{3}$ & 2.5 \\
$L_{\mathrm{y}}$ & 7.29 & $L_{4}$ & 33.6 \\
$H_{\mathrm{x}}$ & 36.5 & $W_{4}$ & 5.1 \\
$H_{\mathrm{y}}$ & 43.1 & $L_{5}$ & 3 \\
$L_{1}$ & 24.6 & $W_{5}$ & 4.1 \\
$W_{1}$ & 6.5 & $L_{\mathrm{f}}$ & 19.9 \\
$L_{2}$ & 27 & $W_{\mathrm{f}}$ & 2.7 \\
\hline \hline
\end{tabular}

0

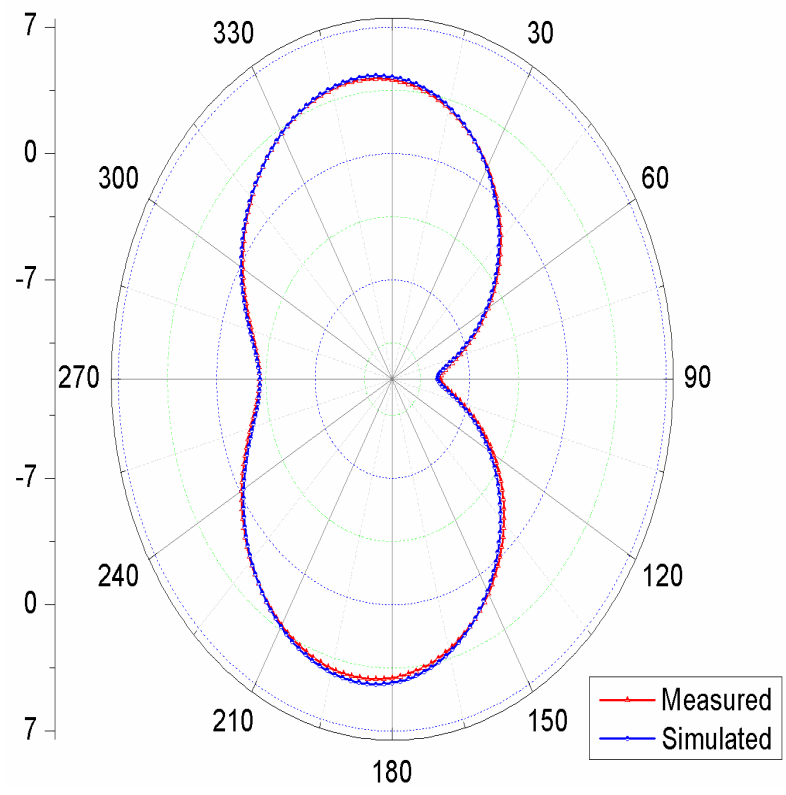

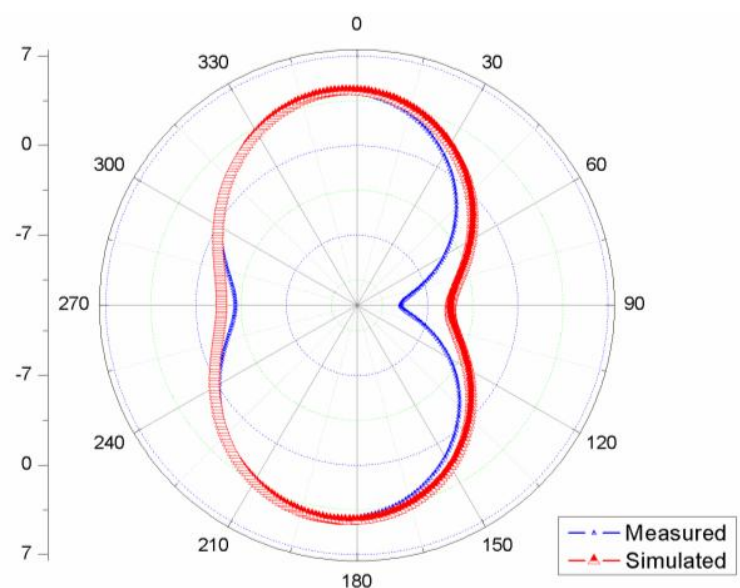

(a)
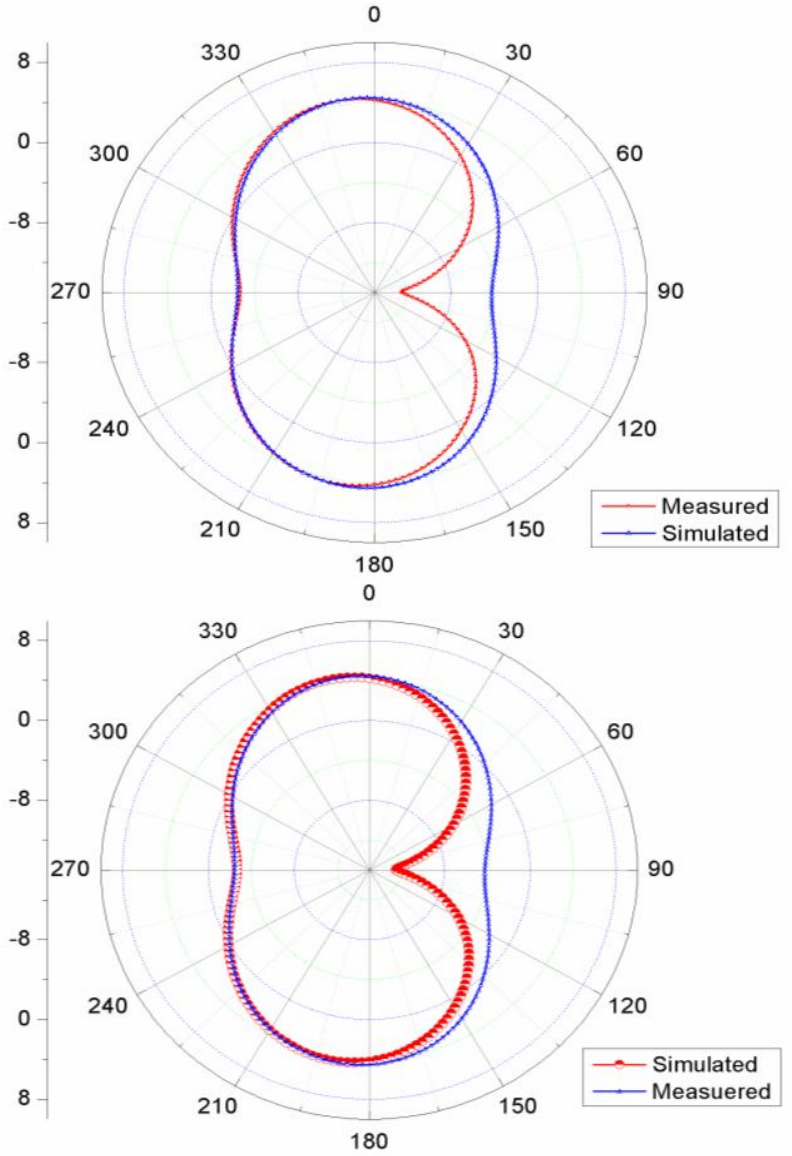

(b)

Figure 3. Simulated and Measured radiation patterns at the different bands of the proposed antenna (a) $2.4 \mathrm{GHz}$, (b) $2.48 \mathrm{GHz}$.

As shown in Figures 3 (a) and (b), compared with the measured radiation patterns at both the lower and upper band in the E-Plane (XZ Plane, $\varphi=00$ ) and the H-Plane (YZ Plane, $\varphi=900$ ), the simulated far-field radiation patterns of the antenna at the lower and upper bands (WLAN: $2.4-2.48 \mathrm{GHz}$ ) are validated. In addition, the figure shows that the simulated and measured patters agree well with each other, which proved the performance of the 
designed antenna Meanwhile, peak gains of measured at 2.4 $\mathrm{GHz}$ and $2.48 \mathrm{GHz}$ are $4.21 \mathrm{~dB}$ and $4.48 \mathrm{~dB}$, which is shown in figure 4 (a) and (b).

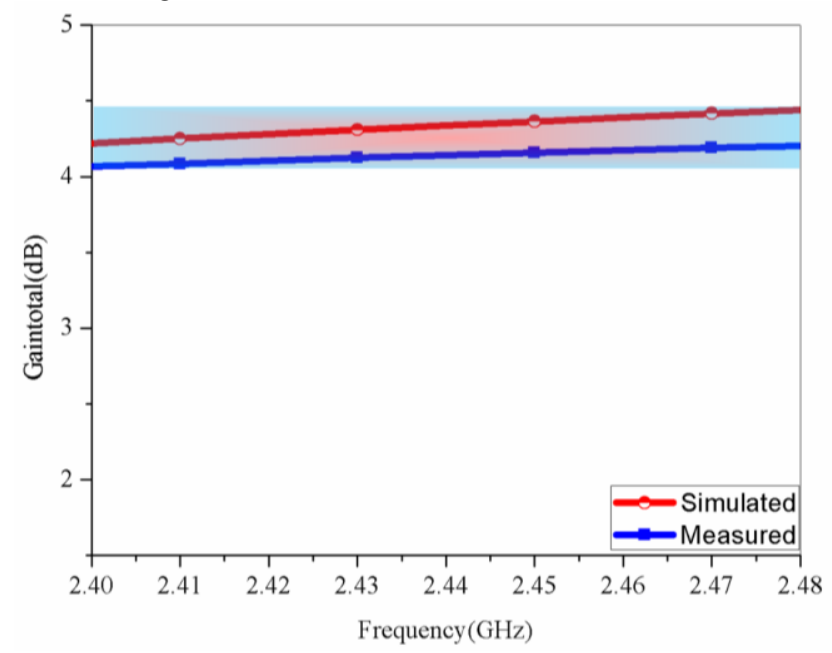

Figure 4. Simulated gain of the proposed antenna at lower and upper bands.

\section{CONCLUSIONS}

In this paper, a novel asymmetric U-Shaped slot antenna fed by CPW with WLAN application is proposed and fabricated. Simulated results show that the proposed antenna can provide a $10-\mathrm{dB}$ bandwidth of $21.8 \%$ from 2.25 to 2.8 $\mathrm{GHz}$, respectively, which have a good agreement with measured data. Results have shown that the proposed antenna perform a wider impendence widths compared with published antenna recently.

\section{REFERENCES}

[1] J. Y. Sze, C. I. G. Hsu, Z. W. Chen, and C. C. Chang, "Broadband CPW-fed circularly polarized square slot antenna with lighteningshaped feed line and inverted-L grounded strips," IEEE Trans. Antennas Propag., 2010,vol. 58, no. 3, pp. 973-977.

[2] Y.W. Liu and P. Hsu, "Broadband circularly polarized square slot antenna fed by co-planar waveguide," Electron. Lett. 2013, vol. 49, no. 16 , pp. $976-977$.
[3] Y. B. Chen, Y. C. Jiao, and F. S. Zhang, "Polarization reconfigurable cpw-fed square slot antenna using pin diodes,"Microw. Opt. Technol. Lett., 2007, vol. 49, no. 6, pp. 1233-1236.

[4] C. J. Wang and C. H. Chen, "CPW-fed stair-shaped slot antennas with circular polarization," IEEE Trans. Antennas Propag., 2009,vol. 57, no. 8, pp. 2483-2486.

[5] S. W. Zhou, P. H. Li, Y. Wang, W. H. Feng, and Z. Q. Liu, "A CPWfed broadband circularly polarized regular-hexagonal slot antenna with L-shape monopole," IEEE Antennas wireless Propag. Lett. , 2011, vol. 10, pp. 1182-1185.

[6] G. H. Li, H. Q. Zhai, Tong Li, Long Li, and C. H. Liang, "CPW-Fed S-Shaped Slot Antenna for Broadband Circular Polarization," IEEE Antennas and wireless Propag Letters, vol. 12, pp. 619-622,2013.

[7] C. H. Chen, Y. C. Jiao, G. Zhao, F. Zhagn, Z. L. Liao, and Y. Tian, "Dual-band dual-sense circularly polarized slot antenna with a Cshaped grounded ship," IEEE Trans. Antennas Propag, vol. 59, no. 4, pp. 1379-1384, Apr. 2011.

[8] J. H. Lu and B. J. Huang, "Planar compact slot antenna with multiband operation for IEEE $802.16 \mathrm{~m}$ application," IEEE Trans. Antennas Propagat., vol. 61, pp. 1411-1414, Mar. 2013

[9] J. L. Chen, K. F. Tong, Allann Al-Armaghany, and J. H. Wang, "A Dual Band Dual Polarization Slot Patch Antenna for GPS and Wi-Fi Applications," IEEE Antennas and wireless Propag Letters, vol. 15, pp. 406-409, 2016.

[10] Y. Ding and K. W. Leung, "Dual-band circularly polarized dual-slot antenna with a dielectric cover," IEEE Trans. Antennas Propag. vol.57, no. 12, pp. 3757-3764, Dec. 2009.

[11] R. V. S. Ram Krishna and Raj Kumar Cimen, "A CPW fed Hexagonal Patch - Slot Antenna for Circular Polarization" IEEE MTT-S Intermational Microwave and RF Conference, pp. 1-4, 14-16 Dec. 2013.

[12] X. L. Bao and M. J. Ammann, "Monofilar spiral slot antenna for dualfrequency dual-sense circular polarization," IEEE Trans. Antennas Propag., vol. 59, no. 8, pp. 3061-3065, Aug. 2011.

[13] Y. L. Mao, S. H. Xu, F. Yang, "A Single-Layer Dual-Band Circularly Polarized Reflectarray with High Aperture Efficiency" IEEE Transactions on Antennas and Propagation, 2015, vol. 63, no. 7, pp. $3317-3320$

[14] J. S. Row, W. L. Liu, and T. R. Chen, "Circular polarization and polarization reconfigurable designs for annular slot antennas," IEEE Trans. Antennas Propag., 2012, vol. 60, no. 12, pp. 5998-6002.

[15] C. H. Chen and E. K. N. Yung "Dual-Band Circulatly-Polarized CPW-Fed Slot Antenna With a Small Frequency Ratio Wide Bandwidths," IEEE Trans. Antennas Propag., 2011, vol. 59, no. 4, pp. 1379-1384 